\title{
浙江省森林生态系统碳储量及其分布特征
}

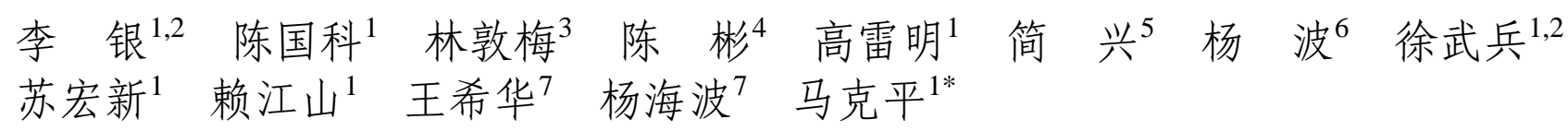

${ }^{1}$ 中国科学院植物研究所植被与环境变化国家重点实验室, 北京 $100093 ;{ }^{2}$ 中国科学院大学, 北京 $100049 ;{ }^{3}$ 重庆大学三峡库区生态环境教育部重点实 验室, 重庆 400044; ${ }^{4}$ 上海辰山植物园, 上海 200062; ${ }^{5}$ 安徽科技学院城建与环境学院, 安徽蚌埠 233300; ${ }^{6}$ 景德镇学院, 江西景德镇 333000; ${ }^{7}$ 华东师 范大学生态与环境科学学院, 上海 200062

摘 要 利用2011-2012年野外标准地实测资料, 结合第八次全国森林资源清查资料, 研究了浙江省森林生态系统碳储量及 其分布特征。结果表明: 浙江省森林生态系统碳储量为 $602.73 \mathrm{Tg}$, 其中乔木层、灌草层、调落物层和土壤层碳储量分别为 $122.88 \mathrm{Tg} 、 16.73 \mathrm{Tg} 、 11.36 \mathrm{Tg}$ 和 $451.76 \mathrm{Tg}$, 分别占生态系统碳储量的 $20.39 \% 、 2.78 \% 、 1.88 \%$ 和 $74.95 \%$; 在各森林类型中, 阔 叶混交林碳储量为 $138.03 \mathrm{Tg}$, 所占比例最大 $(22.90 \%)$; 在森林各龄组中, 幼、中龄林约占浙江省森林生态系统碳储量的 $70.66 \%$, 是碳储量的主要贡献者。浙江省森林生态系统平均碳密度为 $120.80 \mathrm{t} \cdot \mathrm{hm}^{-2}$, 乔木层、灌草层、调落物层和土壤层碳 密度分别为 $24.65 \mathrm{t} \cdot \mathrm{hm}^{-2} 、 3.36 \mathrm{t} \cdot \mathrm{hm}^{-2} 、 2.28 \mathrm{t} \cdot \mathrm{hm}^{-2}$ 和 $90.51 \mathrm{t} \cdot \mathrm{hm}^{-2}$ 。浙江省森林生态系统土壤层碳储量和生态系统碳储量呈极显 著相关关系, 说明土壤层碳储量对浙江省森林生态系统碳储量贡献较大。浙江省天然林乔木层碳密度整体表现为过熟林>成熟 林>近熟林>中龄林>幼龄林, 而人工林乔木层碳密度表现为过熟林>近熟林>成熟林>中龄林>幼龄林。浙江省幼、中龄林林分 面积占比重较大, 占全省森林面积的 $76.76 \%$, 若对现有森林进行更好的经营和管理, 可以增加浙江省森林的碳固存能力。

关键词＼cjkstart森林生态系统；碳储量；碳密度；空间分布；浙江省

引用格式: 李银, 陈国科, 林敦梅, 陈涁, 高雷明, 简兴, 杨波, 徐武兵, 苏宏新, 赖江山, 王希华, 杨海波, 马克平 (2016). 浙江省森林生态系统碳储 量及其分布特征. 植物生态学报, 40, 354-363. doi: 10.17521/cjpe.2015.0193

\section{Carbon storage and its distribution of forest ecosystems in Zhejiang Province, China}

LI Yin ${ }^{1,2}$, CHEN Guo-Ke ${ }^{1}$, LIN Dun-Mei ${ }^{3}$, CHEN Bin ${ }^{4}$, GAO Lei-Ming ${ }^{1}$, JIAN Xing ${ }^{5}$, YANG Bo ${ }^{6}$, XU Wu-Bing ${ }^{1,2}$, SU Hong-Xin ${ }^{1}$, LAI Jiang-Shan ${ }^{1}$, WANG Xi-Hua ${ }^{7}$, YANG Hai-Bo ${ }^{7}$, and MA Ke-Ping ${ }^{1 *}$

${ }^{1}$ State Key Laboratory of Vegetation and Environmental Change, Institute of Botany, Chinese Academy of Sciences, Beijing 100093, China; ${ }^{2}$ University of Chinese Academy of Sciences, Beijing 100049, China; ${ }^{3}$ Key Laboratory of Eco-Environment of Three Gorges Reservior Region, Ministry of Education, Chongqing University, Chongqing 400044, China; ${ }^{4}$ Shanghai Chenshan Botanical Garden, Shanghai 200062, China; ${ }^{5}$ College of Urban Construction and Environment, Anhui Science and Technology University, Bengbu, Anhui 233300, China; ${ }^{6}$ Jingdezhen University, Jingdezhen, Jiangxi 333000, China; and ${ }^{7}$ School of Ecological and Environmental Sciences, East China Normal University, Shanghai 200062, China

\section{Abstract}

Aims The concentration of $\mathrm{CO}_{2}$ and other greenhouse gases in the atmosphere has considerably increased over last century and is set to rise further. Forest ecosystems play a key role in reducing $\mathrm{CO}_{2}$ concentration in the atmosphere and mitigating global climate change. Our objective is to understand carbon storage and its distribution in forest ecosystems in Zhejiang Province, China.

Methods By using the 8th forest resource inventory data and 2011-2012 field investigation data, we estimated carbon storage, density and its distribution in forest ecosystems of Zhejiang Province.

Important findings The carbon storage of forest ecosystems in Zhejiang Province was $602.73 \mathrm{Tg}$, of which $122.88 \mathrm{Tg}$ in tree layer, $16.73 \mathrm{Tg}$ in shrub-herb layer, $11.36 \mathrm{Tg}$ in litter layer and $451.76 \mathrm{Tg}$ in soil layer accounting for $20.39 \%, 2.78 \%, 1.88 \%$ and $74.95 \%$ of the total carbon storage, respectively. The carbon storage of mixed broadleaved forests was $138.03 \mathrm{Tg}$ which ranked the largest (22.90\%) among all forest types. The young and middle aged forests which accounted for $70.66 \%$ of the total carbon storage were the main body of carbon storage in Zhejiang Province. The carbon density of forest ecosystems in Zhejiang Province was $120.80 \mathrm{t} \cdot \mathrm{hm}^{-2}$ and that in tree layer, shrub-herb layer, litter layer and soil layer were $24.65 \mathrm{t} \cdot \mathrm{hm}^{-2}, 3.36 \mathrm{t} \cdot \mathrm{hm}^{-2}, 2.28 \mathrm{t} \cdot \mathrm{hm}^{-2}$ and $90.51 \mathrm{t} \cdot \mathrm{hm}^{-2}$, respectively. The significant relationship between soil organic carbon storage and forest ecosystem carbon storage

收稿日期Received: 2015-06-02 接受日期Accepted: 2015-11-27

* 通信作者Author for correspondence (E-mail: kpma@ibcas.ac.cn) 
indicated that soil carbon played an important role in shaping forest ecosystem carbon density. Carbon density of tree layer increased with age in natural forests, but decreased in the order over-mature $>$ near-mature $>$ mature $>$ middle-aged $>$ young forest in plantations. The proportions of young and middle aged forests were larger than any other age classes. Thereby, the carbon storage of forest ecosystems in Zhejiang Province could be increased through a proper forest management.

Key words forest ecosystem; carbon storage; carbon density; spatial distribution; Zhejiang Province

Citation: Li Y, Chen GK, Lin DM, Chen B, Gao LM, Jian X, Yang B, Xu WB, Su HX, Lai JS, Wang XH, Yang HB, Ma KP (2016). Carbon storage and its distribution of forest ecosystems in Zhejiang Province, China. Chinese Journal of Plant Ecology, 40, $354-363$. doi: 10.17521/cjpe.2015.0193

自工业革命以来，化石燃料的大量燃烧加之土 地利用的改变, 导致大气中的 $\mathrm{CO}_{2}$ 浓度不断升高 (Vitousek, 1994; Rind, 1999; Pope, 2006)。由此引起 的全球气候变暖已成为广泛关注的热点问题之一 (Norby \& Luo, 2006)。陆地生态系统是地球生物圈 三大碳库之一, 在平衡和吸收大气 $\mathrm{CO}_{2}$ 中发挥着重 要作用, 是大气碳的主要汇(Schimel, 1995; 方精云 等, 2001)。森林生态系统是陆地生态系统的主要碳 库，储存了陆地生态系统地上碳库的 $80 \%$ 、地下碳 库的40\% (Malhi et al., 1999), 在调节全球碳平衡以 及减缓全球温室效应等方面起着不可替代的作用 (刘国华等, 2000; Watson et al., 2000)。

目前, 已对全球和区域水平的森林生态系统碳 储量和碳密度开展了大量的研究(Simpson et al., 1993; Dixon et al., 1994; Asner et al., 2010; Pan et al., 2011)。我国也有不少学者发表了森林生态系统碳储 量和碳密度的研究结果(刘国华等, 2000; 周玉荣等, 2000; 方精云等, 2001; Fang et al., 2001, 2007; 王效 科等, 2001; 李克让等, 2003; 赵敏和周广胜, 2004; 李海奎等, 2011; 刘双娜等, 2012), 但这些研究结果 存在很大的差异, 主要原因是植被类型多样, 研究 区域较复杂，估算方法和基础数据存在差异(刘国华 等, 2000; 吕超群和孙书存, 2004)。同时, 以上大部分 研究主要针对乔木层, 而对林下灌草、调落物以及土 壤碳储量和碳密度的关注较少。如果按植被类型、 区域进行多组分的详尽统计, 利用最新森林调查资 料, 可以提高森林生态系统碳储量的估计精度。

目前已开展一系列有关浙江省森林碳储量和碳 密度的研究, 如刘其霞等(2005)、Zhang等(2007)和 张骏等(2010)利用野外样地调查资料估算了浙江省 生态公益林碳密度和碳储量, 张茂震和王广兴 (2008)以及张茂震等(2009)基于森林清查资料研究
了浙江省森林生物量和生产力, 张峰等(2012)基于 地统计学和森林资源连续清查(CFI)样地研究了浙 江省森林碳空间分布：以上研究主要针对浙江省某 些特定的林分类型或者基于清查资料的地上植被碳 密度和碳储量, 而缺乏有关浙江省不同森林生态系 统碳储量和碳密度及其空间分布的较为全面系统的 研究。本文以浙江省森林生态系统为研究对象, 利 用2011-2012年野外标准地实测资料，结合第八次 全国森林资源清查资料，估算各组分的碳储量和碳 密度, 旨在全面了解浙江省的碳储量及碳密度现状, 为区域碳汇的评估和制定科学合理的森林固碳政策 提供基础数据和科学依据。

\section{1 研究地区和研究方法}

\section{1 研究区概况}

浙江省位于我国东南沿海长江三角洲南翼, 属 于亚热带季风湿润气候, 日照充足, 热量丰富, 降 水充沛，雨热同季，冬夏季交替明显。浙江省年平均 气温为 $15-18{ }^{\circ} \mathrm{C}$, 年降水量为 $980-2000 \mathrm{~mm}$, 年日 照时数为 $1710-2100 \mathrm{~h}$ 。地势西南部高, 东北部低, 自西南向东北倾斜, 呈梯级下降; 东北部为长江三 角洲冲积平原, 中部多为丘陵地区, 西南部多为山 区，平均海拔 $800 \mathrm{~m}$ 。全省最高海拔 $1929 \mathrm{~m}$ 。土壤 类型主要为红壤、红黄壤和黄壤, 还有少量的石灰 土、紫色土等(张茂震等, 2009)。

浙江省森林群落类型丰富, 主要有常绿阔叶 林、常绿落叶阔叶混交林、山地矮林, 此外还有落 叶阔叶林、针叶林和竹林等多种植被类型。根据第 八次全国森林资源连续清查成果数据, 浙江省森林 覆盖率达到 $59.07 \%$, 森林面积 601.36 万 $\mathrm{hm}^{2}$, 其中乔 木林面积 410.07 万 $\mathrm{hm}^{2}$, 经济林面积 107.95 万 $\mathrm{hm}^{2}$, 竹林面积 83.34 万 $\mathrm{hm}^{2}$ 。 


\section{2 研究方法}

\subsection{1 样地设置}

本研究采用的森林资源数据源于2009年国家第 八次森林资源清查浙江省的汇总数据。森林资源数 据包含有样地的地理信息、林地信息、森林类型、 林龄、各森林类型面积和蓄积量等。本研究中只包 括乔木林和竹林的碳储量和碳密度数据, 不包括经 济林的碳储量和碳密度数据。

由于全国森林资源清查资料中只有乔木层的相 关数据, 而没有林下植被(灌木和草本)、调落物和土 壤的相关数据, 本研究于2011-2012年, 在浙江省按 照典型取样的方法, 根据浙江省森林资源清查资料 中主要森林类型各龄组的面积和蓄积量比重, 设置 各类型森林的调查样地, 设置面积不小于 $20 \mathrm{~m} \times 30$ $\mathrm{m}$ 的阔叶混交林 42 个、杉木(Cunninghamia lanceolata)林24个、马尾松(Pinus massoniana)林34个、针 阔混交林 60 个、针叶混交林 8 个、软阔林 6 个、硬阔 林18个、栋类(Quercus spp.)林8个、木荷(Schima superba)林16个、樟(Cinnamomum camphora)林3个、 柳杉(Cryptomeria fortune)林6个、其他松类林 3 个和 竹林 12 个, 共 240 个标准样地。样地调查指标包括地 理位置、海拔高度、坡向、坡位、坡度、树种组成、 胸径、树高、林龄、郁闭度、灌木和草本层的物种 组成及覆盖度、土壤容重和土壤剖面等特征。由于 本研究中没有设置柏木(Cupressus funebris)林样地, 其林下灌草层、调落物层和土壤层碳密度为所有针 叶树种样地相应层次的平均值。将标准样地划分为
$10 \mathrm{~m} \times 10 \mathrm{~m}$ 的小样方, 调查各样方内所有乔木个 体，鉴别物种名，测定其胸径和树高。在样地中，对 优势树种按大、中、小径级选择3-5株样木, 按叶、 枝、干、根取样, 同器官混合形成一个样品, 每个样 品鲜质量300 g左右, 带回实验室, 烘干, 测定乔木 树种各器官的碳含量。乔木树种各器官碳含量采用 重铬酸钾-硫酸氧化法(刘光祬等, 1996)测定。

\subsection{2 乔木层碳密度的估算}

乔木层生物量采用生物量-蓄积量转换关系法 (刘国华等, 2000; Fang et al., 2001, 2007; 曾伟生, 2005)进行估算，具体估算公式如下:

$$
B=a V+b
$$

式中 $B 、 V$ 分别为各森林类型单位面积生物量 $\left(\mathrm{t} \cdot \mathrm{hm}^{-2}\right)$ 和单位面积蓄积量 $\left(\mathrm{m}^{3} \cdot \mathrm{hm}^{-2}\right), a$ 和 $b$ 为相应的生物量蓄积量转换参数, 各森林类型的转换参数见表 1 。

将森林清查资料中各森林类型的单位面积蓄 积量代入式(1)中, 求出单位面积生物量, 然后乘以 对应森林类型乔木碳含量即为各森林类型的乔木层 碳密度。由于竹林没有生物量-蓄积量转换模型, 采 用单株平均生物量与总株数之积估算竹林生物量, 单株平均生物量取 $10.44 \mathrm{~kg}$ (张茂震等, 2009)。各森 林类型乔木层碳含量采用本研究实测乔木层优势树 种各器官碳含量的加权平均值(基于各器官所占乔 木生物量的比例)。

\subsection{3 林下灌木、草本和调落物碳密度估算}

在各森林类型样地中随机设置 3 个 $2 \mathrm{~m} \times 2 \mathrm{~m}$ 的 灌木样方, 共计 405个, 记录样方内的物种及其盖

表1 各森林类型林分生物量-蓄积量转换方程

Table 1 Biomass-volume conversion formula for different forest types

\begin{tabular}{|c|c|c|c|c|c|}
\hline 森林类型 Forest type & $a$ & $b$ & $n$ & $R^{2}$ & 参考文献 Reference \\
\hline 马尾松林 Pinus massoniana forest & 0.5034 & 20.547 & 52 & 0.87 & Fang et al., 2007 \\
\hline 其他松类林 Other pines and conifer forests & 0.5168 & 33.238 & 19 & 0.86 & Fang et al., 2007 \\
\hline 杉木林 Cunninghamia lanceolata forest & 0.4652 & 19.141 & 90 & 0.94 & Fang et al., 2007 \\
\hline 柳杉林、水杉林 Cryptomeria fortunei, Metasequoia glyptostroboides forests & 0.4158 & 41.3318 & 30 & 0.79 & Fang et al., 2001 \\
\hline 柏木林 Cupressus funebris forest & 0.6129 & 46.1451 & 19 & 0.87 & Fang et al., 2001 \\
\hline 栎类林 Quercus spp. forest & 1.1453 & 8.5473 & 12 & 0.98 & Fang et al., 2001 \\
\hline 木荷林、樟林 Schima superba, Cinnamomum camphora forests & 1.0357 & 8.0591 & 17 & 0.89 & Fang et al., 2001 \\
\hline 硬阔林 Hardwood forest & 1.1783 & 2.5585 & 17 & 0.95 & Fang et al., 2007 \\
\hline 软阔林 Softwood forest & 0.4754 & 30.603 & 16 & 0.92 & Liu et al., 2000 \\
\hline 针叶混交林 Mixed coniferous forest & 0.5894 & 24.5151 & & & Zeng, 2005 \\
\hline 阔叶混交林 Mixed broadleaved forest & 0.9788 & 5.3764 & 35 & 0.93 & Fang et al., 2007 \\
\hline 针阔叶混交林 Mixed coniferous and broadleaved forest & 0.8136 & 18.466 & 10 & 0.99 & Fang et al., 2001 \\
\hline
\end{tabular}

$a$, 回归方程的常数 $\left(\mathrm{t} \cdot \mathrm{m}^{-3}\right) ; b$, 回归方程的常数 $\left(\mathrm{t} \cdot \mathrm{hm}^{-2}\right) ; n$, 回归方程中所使用的样本数; $R^{2}$, 回归方程的决定系数。

$a$, a constant in the regression model $\left(\mathrm{t} \cdot \mathrm{m}^{-3}\right) ; b$, a constant in the regression model $\left(\mathrm{t} \cdot \mathrm{hm}^{-2}\right)$; $n$, number of trees used in developing the regression model; $R^{2}$, coefficient of determination in the regression model.

www.plant-ecology.com 
度, 然后将样方内所有灌木全部收获, 分根、枝干、 叶称质量, 分别取约 $300 \mathrm{~g}$ 样品称鲜质量。在灌木调 查样方内, 设置 1 个 $1 \mathrm{~m} \times 1 \mathrm{~m}$ 的草本样方, 共计 300 个, 记录样方内物种及其盖度, 然后收获样方内全 部草本, 分地上和地下部分称量, 并分别取约 $300 \mathrm{~g}$ 样品称鲜质量。在乔木样方中, 选择代表地段, 设置 3 个 $1 \mathrm{~m} \times 1 \mathrm{~m}$ 的小样方, 共计701个, 收集样方内的 所有调落物并称量, 取其混合样品约 $300 \mathrm{~g}$ 称鲜质 量。将样地所采集的灌木、草本和调落物样品带回 实验室, $65{ }^{\circ} \mathrm{C}$ 恒温烘干至恒质量, 推算灌木、草本 和调落物的含水率, 根据含水率推算其生物量, 进 而推算生物量密度。取灌木、草本和调落物烘干样 品, 采用重铬酸钾-硫酸氧化法分别测定其碳含量 (刘光崧等, 1996)。灌木、草本和调落物生物量密度 乘以其相应的碳含量得到碳密度。

\subsection{4 土壤层碳密度估算}

在灌木样方内设置一个土壤剖面, 各森林类型 中阔叶混交林 37 个、杉木林 24 个、马尾松林 33 个、 针阔混交林 51 个、针叶混交林 3 个、软阔林 6 个、硬 阔林 12 个、栋类林 5 个、木荷林 12 个、樟林 3 个、柳 杉林 3 个、其他松类林 3 个、竹林 9 个, 共设置剖面 201 个, 每个剖面分为: I层 $(0-10 \mathrm{~cm}) 、 \mathrm{II}$ 层 $(10-20 \mathrm{~cm})$ 、 III层 $(20-30 \mathrm{~cm}) 、 \mathrm{IV}$ 层 $(30-50 \mathrm{~cm})$ 和V层 $(50-100 \mathrm{~cm})$, 分层取样(不足 $1 \mathrm{~m}$ 的取至基岩层, 碳密度按 0 计算), 用环刀法测定土壤容重。在灌木样方内, 利用土钻, 按I层 $(0-10 \mathrm{~cm}) 、 \mathrm{II}$ 层 $(10-20 \mathrm{~cm}) 、 \mathrm{III}$ 层 $(20-30 \mathrm{~cm})$ 、
IV层 $(30-50 \mathrm{~cm})$ 和V层 $(50-100 \mathrm{~cm})$, 每层随机钻取 3-5钻土, 去除石砾和杂物, 合并成一个混合样。同 一样地 3 个灌木样方的同层土样组成该层土壤混合 样品。土壤样品用塑料自封袋密封, 带回实验室, 风 干、研磨、过 20 目和 100 目篮后待测定, 土壤各层次 的碳含量采用重铬酸钾-硫酸氧化法测定(刘光崧等, 1996)。各森林类型土壤有机碳含量垂直分布特征见 表2。各森林类型土壤碳密度的计算公式为:

$$
S O C=\sum_{i=1}^{n} B_{i} \times C_{i} \times\left(1-G_{i}\right) \times H_{i} / 10
$$

式中, $S O C$ 为各森林类型土壤有机碳密度 $\left(\mathrm{t} \cdot \mathrm{hm}^{-2}\right), B_{i}$ 为第 $i$ 层土壤容重 $\left(\mathrm{g} \cdot \mathrm{cm}^{-3}\right), C_{i}$ 为第 $i$ 层土壤碳含量 $\left(\mathrm{g} \cdot \mathrm{kg}^{-1}\right), H_{i}$ 为第 $i$ 层土壤的厚度 $(\mathrm{cm}), G_{i}$ 为第 $i$ 层直径 大于 $2 \mathrm{~mm}$ 的砾石质量分数(\%)。

\subsection{5 森林生态系统碳储量计算}

利用植被类型外推法估算浙江省各森林类型灌 木层、草本层、调落物层和土壤层碳储量(周玉荣等, 2000; 王新闯等, 2011), 估算公式如下:

$$
S O C_{i}=C_{i} \times S_{i}
$$

式中, $S O C_{i}$ 为浙江省第 $i$ 类型森林灌草层、调落物层 和土壤层碳储量; $C_{i}$ 为第 $i$ 类型森林灌草层、调落物 层和土壤层碳密度; $S_{i}$ 为第 $i$ 类型森林面积。

\section{2 结果}

\section{1 浙江省森林生态系统碳储量分布特征}

浙江省森林生态系统平均碳密度为 $120.80 \mathrm{t} \cdot \mathrm{hm}^{-2}$,

表2 浙江省不同森林类型土壤有机碳含量垂直分布 $\left(\mathrm{g} \cdot \mathrm{kg}^{-1}\right.$, 平均值土标准偏差)

\begin{tabular}{|c|c|c|c|c|c|}
\hline \multirow[t]{2}{*}{ 森林类型 Forest type } & \multicolumn{5}{|c|}{ 土壤深度 Soil depth (cm) } \\
\hline & $0-10 \mathrm{~cm}$ & $10-20 \mathrm{~cm}$ & $20-30 \mathrm{~cm}$ & $30-50 \mathrm{~cm}$ & $50-100 \mathrm{~cm}$ \\
\hline 樟林 Cinnamomum camphora forest & $28.83 \pm 1.09$ & $11.41 \pm 0.87$ & $9.47 \pm 2.35$ & $6.50 \pm 1.30$ & $4.37 \pm 0.26$ \\
\hline 柳杉林 Cryptomeria fortunei forest & $31.13 \pm 3.21$ & $21.77 \pm 1.89$ & $17.31 \pm 2.41$ & $9.91 \pm 1.48$ & $8.32 \pm 0.17$ \\
\hline 软阔林 Softwood forest & $18.28 \pm 9.74$ & $14.26 \pm 8.71$ & $14.10 \pm 8.11$ & $12.11 \pm 6.32$ & $13.30 \pm 2.74$ \\
\hline 柏木林 Cupressus funebris forest & $35.21 \pm 10.67$ & $19.76 \pm 7.57$ & $11.09 \pm 3.57$ & $7.23 \pm 2.27$ & $7.72 \pm 4.50$ \\
\hline 硬阔林 Hardwood forest & $23.72 \pm 5.73$ & $11.55 \pm 4.58$ & $7.57 \pm 2.60$ & $5.82 \pm 1.93$ & $4.33 \pm 1.67$ \\
\hline 木荷林 Schima superba forest & $16.74 \pm 2.37$ & $10.72 \pm 2.61$ & $8.83 \pm 1.23$ & $5.45 \pm 0.56$ & $4.15 \pm 0.43$ \\
\hline 其他松类林 Other pines and conifer forests & $20.97 \pm 8.21$ & $14.20 \pm 5.49$ & $8.97 \pm 5.09$ & $6.26 \pm 0.68$ & $5.93 \pm 0.80$ \\
\hline 栋类林 Quercus spp. forest & $20.29 \pm 3.32$ & $10.08 \pm 2.05$ & $6.04 \pm 1.71$ & $5.36 \pm 0.41$ & $4.35 \pm 0.37$ \\
\hline 针叶混交林 Mixed coniferous forest & $19.82 \pm 9.37$ & $10.05 \pm 3.91$ & $7.74 \pm 3.09$ & $5.63 \pm 1.96$ & $5.29 \pm 2.97$ \\
\hline 针阔叶混交林 Mixed coniferous and broadleaved forest & $16.22 \pm 9.53$ & $8.84 \pm 6.06$ & $6.42 \pm 4.57$ & $5.16 \pm 3.59$ & $4.26 \pm 2.51$ \\
\hline 马尾松林 Pinus massoniana forest & $21.34 \pm 5.97$ & $13.01 \pm 3.83$ & $9.27 \pm 2.64$ & $7.64 \pm 2.73$ & $6.19 \pm 2.62$ \\
\hline 杉木林 Cunninghamia lanceolata forest & $14.11 \pm 2.92$ & $9.17 \pm 1.73$ & $8.07 \pm 4.89$ & $4.78 \pm 1.86$ & $4.02 \pm 1.21$ \\
\hline 竹林 Bamboo forest & $28.76 \pm 10.83$ & $14.42 \pm 5.77$ & $9.97 \pm 3.71$ & $7.31 \pm 2.99$ & $5.60 \pm 2.40$ \\
\hline
\end{tabular}

Table 2 Vertical distribution of soil organic carbon content of different forest types in Zhejiang Province (g.kg-1 mean $\pm S D)$ 
其中乔木层、灌草层、调落物层和土壤层碳密度分 别为 $24.65 \mathrm{t} \cdot \mathrm{hm}^{-2} 、 3.36 \mathrm{t} \cdot \mathrm{hm}^{-2} 、 2.28 \mathrm{t} \cdot \mathrm{hm}^{-2}$ 和 90.51 $\mathrm{t} \cdot \mathrm{hm}^{-2}$ (表3)。在乔木层中, 柏木林碳密度最大, 为 $47.95 \mathrm{t} \cdot \mathrm{hm}^{-2}$; 樟林碳密度最小, 为 $17.57 \mathrm{t} \cdot \mathrm{hm}^{-2}$ 。在灌 草层中, 针叶混交林碳密度最大, 为 $6.82 \mathrm{t} \cdot \mathrm{hm}^{-2}$; 柳 杉林碳密度最小, 为 $0.86 \mathrm{t} \cdot \mathrm{hm}^{-2}$, 前者碳密度是后者 的8倍。在调落物层中, 针叶混交林的碳密度最大, 为 $3.67 \mathrm{t} \cdot \mathrm{hm}^{-2}$; 竹林碳密度最小, 为 $0.63 \mathrm{t} \cdot \mathrm{hm}^{-2}$ 。在土 壤层中, 柳杉林的碳密度最大, 为 $155.83 \mathrm{t} \cdot \mathrm{hm}^{-2}$; 竹 林碳密度最小, 为71.63 $\mathrm{t} \cdot \mathrm{hm}^{-2}$ 。生态系统碳密度柳 杉林最大, 为 $204.15 \mathrm{t} \cdot \mathrm{hm}^{-2}$; 竹林碳密度最小, 为 $96.98 \mathrm{t} \cdot \mathrm{hm}^{-2}$ (表3)。

浙江省森林生态系统碳储量为 $602.73 \mathrm{Tg}$, 其中 乔木层、灌草层、调落物层和土壤层碳储量分别为 $122.88 \mathrm{Tg} 、 16.73 \mathrm{Tg} 、 11.36 \mathrm{Tg}$ 和 $451.76 \mathrm{Tg}$, 分别占 生态系统碳储量的 $20.39 \% 、 2.78 \% 、 1.88 \%$ 和 $74.95 \%$ (表3)。土壤层和乔木层碳储量之和占浙江省森林生 态系统碳储量的95.34\%, 是浙江省森林生态系统的 主要碳库。阔叶混交林、杉木林、马尾松林和竹林
碳储量分别占浙江省森林生态系统碳储量的 $22.90 \% 、 17.09 \% 、 14.73 \%$ 和 $14.21 \%$, 是浙江省森林 生态系统碳储量的主要贡献者, 这主要是因为这 4类森林面积较大，共占全省森林面积的 $70.60 \%$ (表3)。

\section{2 浙江省各森林类型乔木层各龄组碳储量}

浙江省天然乔木层碳密度整体表现为过熟林> 成熟林 $>$ 近熟林 $>$ 中龄林 $>$ 幼龄林 $($ 表 4 ; 图 $1 \mathrm{~A})$, 而人 工林乔木层碳密度整体表现为过熟林 $>$ 近熟林 $>$ 成 熟林>中龄林>幼龄林 (表5; 图1A); 同一龄组的碳 密度, 除近熟林外, 均表现为天然林乔木层大于人 工林(图1A), 说明天然林较人工林有更强的碳储存 能力。在天然林中, 除阔叶混交林表现为中龄林碳 密度最大外, 其他各森林类型碳密度均表现为随林 龄增加而增加; 栋类中龄林碳密度在浙江省各森林 类型各龄组乔木层中最大, 为 $97.51 \mathrm{t} \cdot \mathrm{hm}^{-2}$, 杉木幼 龄林碳密度最小, 为 $11.12 \mathrm{t} \cdot \mathrm{hm}^{-2}$ (表4)。在人工林 中, 杉木乔木层碳密度表现为过熟林>近熟林>成熟 林>中龄林>幼龄林, 柳杉林乔木层碳密度表现为过

表3 浙江省森林生态系统碳储量和碳密度(平均值土标准偏差)

Table 3 Carbon storage and density of forest ecosystems in Zhejiang Province (mean $\pm S D$ )

\begin{tabular}{|c|c|c|c|c|c|c|c|c|}
\hline \multirow{2}{*}{$\begin{array}{l}\text { 森林类型 } \\
\text { Forest type }\end{array}$} & \multirow{2}{*}{$\begin{array}{c}\text { 面积 } \\
\text { Area } \\
\left(100 \mathrm{hm}^{2}\right)\end{array}$} & \multicolumn{5}{|c|}{ 碳密度 Carbon density $\left(\mathrm{t} \cdot \mathrm{hm}^{-2}\right)$} & \multirow{2}{*}{$\begin{array}{c}\text { 生态系统碳储量 } \\
\text { Forest ecosystem } \\
\text { carbon storage } \\
\text { (Tg) }\end{array}$} & \multirow{2}{*}{$\begin{array}{l}\text { 样本数 } \\
\text { Sample } \\
\text { number }\end{array}$} \\
\hline & & $\begin{array}{c}\text { 乔木层 } \\
\text { Tree } \\
\text { layer }\end{array}$ & $\begin{array}{l}\text { 灌草层 } \\
\text { Shrub-herb } \\
\text { layer }\end{array}$ & $\begin{array}{l}\text { 调落物层 } \\
\text { Litter layer }\end{array}$ & $\begin{array}{l}\text { 土壤层 } \\
\text { Soil layer }\end{array}$ & $\begin{array}{c}\text { 森林生态 } \\
\text { 系统 Forest } \\
\text { ecosystem }\end{array}$ & & \\
\hline 樟林 Cinnamomum camphora forest & 24 & 17.57 & $3.07 \pm 1.94$ & $3.47 \pm 0.84$ & $86.37 \pm 3.01$ & 110.48 & 0.27 & 3 \\
\hline 柳杉林 Cryptomeria fortunei forest & 167 & 46.04 & $0.86 \pm 0.07$ & $1.42 \pm 0.58$ & $155.83 \pm 6.53$ & 204.15 & 3.41 & 6 \\
\hline 软阔林 Softwood forest & 216 & 19.15 & $1.70 \pm 0.37$ & $0.95 \pm 0.41$ & $147.61 \pm 18.21$ & 169.42 & 3.66 & 6 \\
\hline 柏木林 Cupressus funebris forest & 240 & 47.95 & $4.06 \pm 1.03$ & $2.48 \pm 0.96$ & $98.30 \pm 16.24$ & 152.79 & 3.67 & 5 \\
\hline 硬阔林 Hardwood forest & 671 & 23.08 & $1.84 \pm 0.88$ & $2.13 \pm 0.69$ & $115.92 \pm 26.93$ & 142.97 & 9.59 & 18 \\
\hline 木荷林 Schima superba forest & 744 & 30.91 & $3.41 \pm 1.35$ & $2.66 \pm 1.06$ & $81.09 \pm 27.44$ & 118.07 & 8.78 & 16 \\
\hline $\begin{array}{l}\text { 其他松类林 } \\
\text { Other pines and conifer forests }\end{array}$ & 1366 & 29.42 & $5.14 \pm 1.63$ & $2.63 \pm 1.82$ & $71.66 \pm 7.63$ & 108.84 & 14.87 & 3 \\
\hline 栋类林 Quercus spp. forest & 2030 & 23.38 & $2.55 \pm 1.64$ & $2.08 \pm 0.55$ & $109.19 \pm 6.94$ & 137.20 & 27.85 & 8 \\
\hline 针叶混交林 Mixed coniferous forest & 3520 & 29.42 & $6.82 \pm 1.35$ & $3.67 \pm 2.01$ & $84.64 \pm 7.62$ & 124.55 & 43.84 & 8 \\
\hline $\begin{array}{l}\text { 针阔叶混交林 } \\
\text { Mixed coniferous and broadleaved forest }\end{array}$ & 5676 & 28.15 & $3.89 \pm 1.54$ & $2.77 \pm 1.25$ & $90.81 \pm 31.41$ & 125.62 & 71.30 & 60 \\
\hline 马尾松林 Pinus massoniana forest & 8116 & 21.61 & $5.38 \pm 1.78$ & $2.00 \pm 1.20$ & $80.40 \pm 44.30$ & 109.39 & 88.78 & 34 \\
\hline 杉木林 Cunninghamia lanceolata forest & 8209 & 21.72 & $2.11 \pm 0.83$ & $2.68 \pm 1.09$ & $98.96 \pm 27.14$ & 125.47 & 103.00 & 24 \\
\hline 竹林 Bamboo forest & 8834 & 23.78 & $0.94 \pm 0.08$ & $0.63 \pm 0.19$ & $71.63 \pm 18.17$ & 96.98 & 85.67 & 12 \\
\hline 阔叶混交林 Mixed broadleaved forest & 10028 & 25.10 & $3.43 \pm 0.89$ & $2.88 \pm 1.86$ & $106.24 \pm 27.30$ & 137.65 & 138.03 & 42 \\
\hline $\begin{array}{l}\text { 加权平均值 } \\
\text { Weighted average }\left(\mathrm{t} \cdot \mathrm{hm}^{-2}\right)\end{array}$ & & 24.65 & 3.36 & 2.28 & 90.51 & 120.80 & & \\
\hline 合计 Total (Tg) & 49841 & 122.88 & 16.73 & 11.36 & 451.76 & & 602.73 & \\
\hline $\begin{array}{l}\text { 各层碳储量占总碳储量的比例 } \\
\text { The corresponding proportions of carbon } \\
\text { storage in different layers (\%) }\end{array}$ & & 20.39 & 2.78 & 1.88 & 74.95 & & 100.00 & \\
\hline
\end{tabular}

乔木层碳储量数据来源于森林资源清查资料, 而灌草层、调落物层和土壤层碳储量数据来源于野外实测数据。

The carbon storage in the tree layer was estimated by forest resources inventory data, and that in the shrub-herb layer, litter layer and soil layer were estimated by field investigation data.

www.plant-ecology.com 
表4 浙江省天然林乔木层各龄组碳储量和碳密度

Table 4 Carbon storage and density of tree layer for different age natural forests in Zhejiang Province

\begin{tabular}{|c|c|c|c|c|c|c|c|c|c|c|}
\hline \multirow[t]{2}{*}{$\begin{array}{l}\text { 森林类型 } \\
\text { Forest type }\end{array}$} & \multicolumn{2}{|c|}{$\begin{array}{c}\text { 幼龄林 } \\
\text { Young forest }\end{array}$} & \multicolumn{2}{|c|}{$\begin{array}{c}\text { 中龄林 } \\
\text { Middle-aged forest } \\
\end{array}$} & \multicolumn{2}{|c|}{$\begin{array}{c}\text { 近熟林 } \\
\text { Near-mature forest }\end{array}$} & \multicolumn{2}{|c|}{$\begin{array}{c}\text { 成熟林 } \\
\text { Mature forest }\end{array}$} & \multicolumn{2}{|c|}{$\begin{array}{c}\text { 过熟林 } \\
\text { Over-mature forest }\end{array}$} \\
\hline & $\begin{array}{l}\text { 碳密度 } \\
\text { Carbon } \\
\text { density } \\
\left(\mathrm{t} \cdot \mathrm{hm}^{-2}\right)\end{array}$ & $\begin{array}{c}\text { 碳储量 } \\
\text { Carbon } \\
\text { storage } \\
\text { (Tg) }\end{array}$ & $\begin{array}{l}\text { 碳密度 } \\
\text { Carbon } \\
\text { density } \\
\left(\mathrm{t} \cdot \mathrm{hm}^{-2}\right)\end{array}$ & $\begin{array}{c}\text { 碳储量 } \\
\text { Carbon } \\
\text { storage } \\
\text { (Tg) }\end{array}$ & $\begin{array}{l}\text { 碳密度 } \\
\text { Carbon } \\
\text { density } \\
\left(\mathrm{t} \cdot \mathrm{hm}^{-2}\right)\end{array}$ & $\begin{array}{c}\text { 碳储量 } \\
\text { Carbon } \\
\text { storage } \\
(\mathrm{Tg})\end{array}$ & $\begin{array}{l}\text { 碳密度 } \\
\text { Carbon } \\
\text { density } \\
\left(\mathrm{t} \cdot \mathrm{hm}^{-2}\right)\end{array}$ & $\begin{array}{c}\text { 碳储量 } \\
\text { Carbon } \\
\text { storage } \\
\text { (Tg) }\end{array}$ & $\begin{array}{l}\text { 碳密度 } \\
\text { Carbon } \\
\text { density } \\
\left(\mathrm{t} \cdot \mathrm{hm}^{-2}\right)\end{array}$ & $\begin{array}{c}\text { 碳储量 } \\
\text { Carbon } \\
\text { storage } \\
\text { (Tg) }\end{array}$ \\
\hline 其他松类林 Other pines and conifer forests & 17.72 & 0.21 & 31.00 & 0.59 & 44.52 & 1.18 & & & & \\
\hline 马尾松林 Pinus massoniana forest & 15.06 & 2.09 & 22.05 & 7.92 & 27.13 & 4.94 & 43.74 & 1.05 & & \\
\hline 杉木林 Cunninghamia lanceolata forest & 11.12 & 0.29 & 16.14 & 1.27 & 20.28 & 1.21 & 24.55 & 0.94 & 39.33 & 0.09 \\
\hline 栋类林 Quercus spp. forest & 21.95 & 4.35 & 97.51 & 0.22 & & & & & & \\
\hline 木荷林 Schima superba forest & 18.82 & 0.59 & 40.48 & 1.46 & 72.19 & 0.17 & & & & \\
\hline 硬阔林 Hardwood forest & 19.45 & 0.89 & 38.93 & 0.46 & & & & & & \\
\hline 软阔林 Softwood forest & & & & & 16.75 & 0.08 & 22.45 & 0.11 & & \\
\hline 针叶混交林 Mixed coniferous forest & 15.32 & 0.37 & 25.36 & 2.73 & 36.70 & 1.76 & 39.45 & 0.95 & 65.74 & 0.16 \\
\hline 阔叶混交林 Mixed broadleaved forest & 21.54 & 18.36 & 45.17 & 5.61 & 43.03 & 0.20 & 30.53 & 0.15 & & \\
\hline $\begin{array}{l}\text { 针阔叶混交林 } \\
\text { Mixed coniferous and broadleaved forest }\end{array}$ & 22.33 & 4.60 & 31.15 & 6.71 & 46.84 & 2.58 & 37.99 & 0.36 & & \\
\hline 加权平均值 Weighted average $\left(\mathrm{t} \cdot \mathrm{hm}^{-2}\right)$ & 20.69 & & 28.27 & & 31.64 & & 33.69 & & 52.54 & \\
\hline 合计 Total (Tg) & & 31.75 & & 26.98 & & 12.05 & & 3.45 & & 0.25 \\
\hline
\end{tabular}

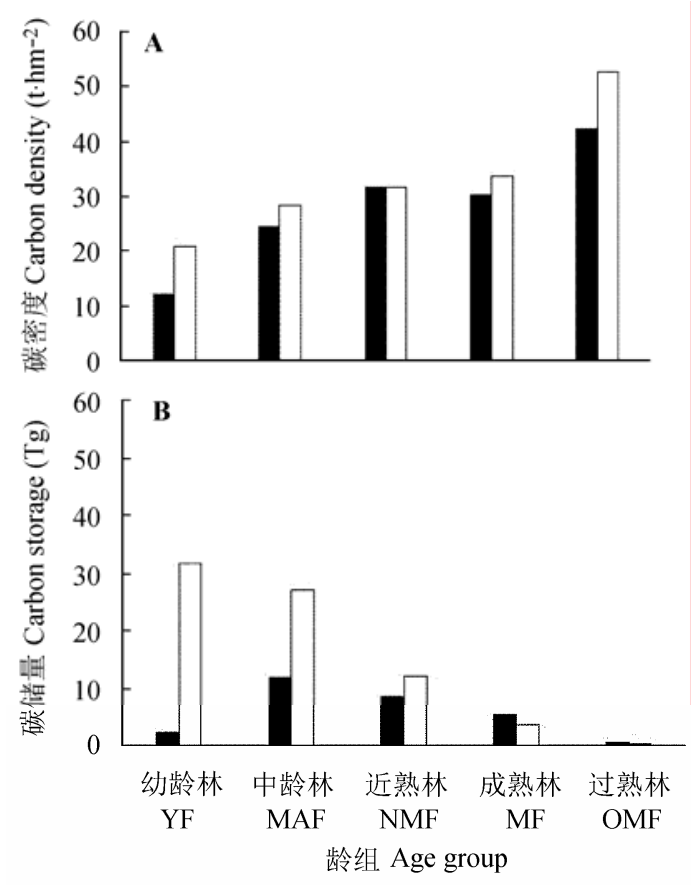

- 人工林 Planted forest 口天然林 Natural forest

图1 浙江省天然林、人工林乔木层各龄组碳密度(A)和碳储量 $(B)$ 。

Fig. 1 Carbon density (A) and carbon storage (B) of tree layer for different age natural and planted forests in Zhejiang Province. YF, MAF, NMF, MF, OMF refer to young forest, middle-aged forest, near-mature forest, mature forest, and over-mature forest, respectively.

熟林>成熟林>幼龄林>近熟林, 阔叶混交林表现为中 龄林>近熟林>幼龄林, 针阔叶混交林表现为近熟林> 成熟林 $>$ 中龄林 $>$ 幼龄林, 其他林分类型表现为碳密 度随林龄增加而增加(表5)。
浙江省天然林乔木层主要为幼龄林和中龄林, 占全省天然林乔木碳储量的 $78.86 \%$ ，其中幼龄林碳 储量最高, 为 $31.75 \mathrm{Tg}$; 中龄林次之, 为 $26.98 \mathrm{Tg}$ (表 4)。人工林乔木层主要以中龄林和近熟林为主，占全 省人工林乔木层碳储量的 $71.44 \%$; 其中中龄林碳储 量最高, 为 $11.96 \mathrm{Tg}$; 过熟林最低, 为 $0.50 \mathrm{Tg}$ (表5)。 浙江省天然林乔木层碳储量(74.48 Tg)远高于人工林 乔木层碳储量 $(28.41 \mathrm{Tg})$, 前者是后者的2.62倍, 说 明天然林是浙江省碳储量的主要贡献者(图1B)。

\section{3 浙江省森林生态系统各组分碳储量相关性分析}

浙江省森林生态系统乔木层碳储量与灌草层和 土壤层碳储量相关性不显著, 与森林生态系统碳储 量呈显著正相关关系 $(p<0.05)$, 而与调落物层碳储 量呈负相关关系; 灌草层碳储量与调落物碳储量呈 极显著正相关关系 $(p<0.01)$, 而与土壤层和森林生 态系统碳储量呈负相关关系; 调落物层碳储量与土 壤层和森林生态系统碳储量的相关性不显著; 土壤 层碳储量与森林生态系统碳储量呈极显著相关关系 $(p<0.01)$, 且相关性系数较大, 说明土壤层碳储量 对整个森林生态系统碳储量的贡献最大(表6)。

\section{3 讨论}

\section{1 浙江省森林生态系统碳储量在全国的地位}

森林生态系统在固定和平衡大气中的 $\mathrm{CO}_{2}$ 、减 缓全球气候变化中起着重要作用。周玉荣等(2000)通 
表5 浙江省人工林乔木层各龄组碳储量和碳密度

Table 5 Carbon storage and density of tree layer for different age planted forests in Zhejiang Province

\begin{tabular}{|c|c|c|c|c|c|c|c|c|c|c|}
\hline \multirow[t]{2}{*}{$\begin{array}{l}\text { 森林类型 } \\
\text { Forest type }\end{array}$} & \multicolumn{2}{|c|}{$\begin{array}{c}\text { 幼龄林 } \\
\text { Young forest }\end{array}$} & \multicolumn{2}{|c|}{$\begin{array}{c}\text { 中龄林 } \\
\text { Middle-aged forest }\end{array}$} & \multicolumn{2}{|c|}{$\begin{array}{c}\text { 近熟林 } \\
\text { Near-mature forest }\end{array}$} & \multicolumn{2}{|c|}{$\begin{array}{c}\text { 成熟林 } \\
\text { Mature forest }\end{array}$} & \multicolumn{2}{|c|}{$\begin{array}{c}\text { 过熟林 } \\
\text { Over-mature forest }\end{array}$} \\
\hline & $\begin{array}{l}\text { 碳密度 } \\
\text { Carbon } \\
\text { density } \\
\left(\mathrm{t} \cdot \mathrm{hm}^{-2}\right)\end{array}$ & $\begin{array}{c}\text { 碳储量 } \\
\text { Carbon } \\
\text { storage } \\
(\mathrm{Tg})\end{array}$ & $\begin{array}{l}\text { 碳密度 } \\
\text { Carbon } \\
\text { density } \\
\left(\mathrm{t} \cdot \mathrm{hm}^{-2}\right)\end{array}$ & $\begin{array}{c}\text { 碳储量 } \\
\text { Carbon } \\
\text { storage } \\
\text { (Tg) }\end{array}$ & $\begin{array}{l}\text { 碳密度 } \\
\text { Carbon } \\
\text { density } \\
\left(\mathrm{t} \cdot \mathrm{hm}^{-2}\right)\end{array}$ & $\begin{array}{c}\text { 碳储量 } \\
\text { Carbon } \\
\text { storage } \\
(\mathrm{Tg})\end{array}$ & $\begin{array}{l}\text { 碳密度 } \\
\text { Carbon } \\
\text { density } \\
\left(\mathrm{t} \cdot \mathrm{hm}^{-2}\right)\end{array}$ & $\begin{array}{c}\text { 碳储量 } \\
\text { Carbon } \\
\text { storage } \\
\text { (Tg) }\end{array}$ & $\begin{array}{l}\text { 碳密度 } \\
\text { Carbon } \\
\text { density } \\
\left(\mathrm{t} \cdot \mathrm{hm}^{-2}\right)\end{array}$ & $\begin{array}{c}\text { 碳储量 } \\
\text { Carbon } \\
\text { storage } \\
\text { (Tg) }\end{array}$ \\
\hline 其他松类林 Other pines and conifer forests & 17.07 & 0.37 & 24.63 & 1.01 & 32.45 & 0.54 & & & & \\
\hline 马尾松林 Pinus massoniana forest & 11.20 & 0.16 & 18.18 & 0.78 & 20.37 & 0.88 & 42.05 & 0.30 & & \\
\hline 杉木林 Cunninghamia lanceolata forest & 9.87 & 0.78 & 22.16 & 5.78 & 31.76 & 4.64 & 26.63 & 3.18 & 35.09 & 0.33 \\
\hline 柳杉林 Cryptomeria fortunei forest & 30.06 & 0.14 & & & 26.83 & 0.06 & 48.62 & 0.35 & 71.35 & 0.17 \\
\hline 柏木林 Cupressus funebris forest & & & 45.89 & 0.88 & 54.98 & 0.26 & & & & \\
\hline 栋类林 Quercus spp. forest & & & 41.07 & 0.10 & & & & & & \\
\hline 樟林 Cinnamomum camphora forest & 16.75 & 0.04 & & & & & & & & \\
\hline 木荷林 Schima superba forest & 3.99 & 0.01 & 38.48 & 0.09 & & & & & & \\
\hline 硬阔林 Hardwood forest & 6.12 & 0.06 & & & & & & & & \\
\hline 软阔林 Softwood forest & 16.03 & 0.08 & 17.40 & 0.13 & & & & & & \\
\hline 针叶混交林 Mixed coniferous forest & 12.29 & 0.09 & 29.49 & 1.84 & 36.58 & 1.57 & 36.71 & 1.23 & & \\
\hline 阔叶混交林 Mixed broadleaved forest & 18.85 & 0.11 & 44.54 & 0.21 & 38.20 & 0.18 & & & & \\
\hline 针阔叶混交林 & 13.55 & 0.29 & 25.14 & 1.02 & 44.26 & 0.42 & 32.32 & 0.31 & & \\
\hline $\begin{array}{l}\text { Mixed coniferous and broadleaved forest } \\
\text { 加权平均值 Weighted average }\left(\mathrm{t} \cdot \mathrm{hm}^{-2}\right)\end{array}$ & 12.20 & & 24.48 & & 31.68 & & 30.35 & & 42.40 & \\
\hline 合计 Total (Tg) & & 2.13 & & 11.84 & & 8.57 & & 5.37 & & 0.50 \\
\hline
\end{tabular}

表6 浙江省森林生态系统各组分碳储量相关性分析

Table 6 Correlation analysis among carbon storage of different carbon pools of forest ecosystem in Zhejiang Province

\begin{tabular}{|c|c|c|c|c|c|}
\hline & $\begin{array}{c}\text { 乔木层 } \\
\text { Tree layer } \\
\end{array}$ & $\begin{array}{c}\text { 灌草层 } \\
\text { Shrub-herb layer } \\
\end{array}$ & $\begin{array}{l}\text { 调落物层 } \\
\text { Litter layer } \\
\end{array}$ & $\begin{array}{c}\text { 土壤层 } \\
\text { Soil layer } \\
\end{array}$ & $\begin{array}{c}\text { 森林生态系统 } \\
\text { Forest ecosystem }\end{array}$ \\
\hline 乔木层 Tree layer & 1 & 0.048 & -0.021 & 0.226 & $0.530^{*}$ \\
\hline 灌草层 Shrub-herb layer & & 1 & $0.679^{* *}$ & $-0.560^{*}$ & -0.416 \\
\hline 凋落物层 Litter layer & & & 1 & -0.411 & -0.311 \\
\hline 土壤层 Soil layer & & & & 1 & $0.942^{* *}$ \\
\hline 森林生态系统 Forest ecosystem & & & & & 1 \\
\hline
\end{tabular}

*, 显著相关 $(p<0.05) ; * *$, 极显著相关 $(p<0.01)$ 。

*, correlation is significant at $p<0.05$ level; **, correlation is significant at $p<0.01$ level.

过广泛收集资料得到我国森林生态系统碳储量为 $281.16 \times 10^{8} \mathrm{t}$, 其中植被碳储量为 $62.00 \times 10^{8} \mathrm{t}$, 调 落物碳储量为 $8.92 \times 10^{8} \mathrm{t}$, 土壤碳储量为 $210.23 \times$ $10^{8} \mathrm{t}$ 。本研究通过野外实际调查, 结合全国第八次 森林资源清查数据, 估算得到浙江省森林生态系统 碳储量为 $620.73 \mathrm{Tg}$, 约占全国森林生态系统碳储量 的 $2.14 \%$, 低于陕西省的790.75 Tg (崔高阳等, 2015) 和吉林省的1 $820.413 \mathrm{Tg}$ (王新闯等, 2011)。浙江省 森林生态系统碳密度为 $120.80 \mathrm{t} \cdot \mathrm{hm}^{-2}$, 低于我国森 林生态系统平均碳密度 $258.83 \mathrm{t} \cdot \mathrm{hm}^{-2}$ (周玉荣等, 2000), 也低于吉林省的 $225.30 \mathrm{t} \cdot \mathrm{hm}^{-2}$ (王新闯等, 2011)、陕西省的 $123.70 \mathrm{t} \cdot \mathrm{hm}^{-2}$ (崔高阳等, 2015)和海 南省的 $163.7 \mathrm{t} \cdot \mathrm{hm}^{-2}$ (Ren et al., 2014)。浙江省森林生 态系统碳密度低于以上省份, 主要是因为幼、中龄 www.plant-ecology.com
林在全省森林面积中所占比重较大。根据第八次全 国森林资源清查资料数据, 浙江省幼、中龄林面积 占全省森林面积的 $76.76 \%$ 。浙江省在新中国成立以 前山林遭到严重破坏, 新中国成立后虽进行了大规 模的封山育林、造林，但改革开放以后，浙江省经济 高速发展，森林采伐消耗较大，森林处于恢复期， 普遍林龄较小(刘其霞等, 2005)。然而从另一个角度 来看, 虽然幼、中龄林比例大, 但其生长速度快, 经 过合理的森林经营管理, 这部分森林碳密度会逐渐 增大, 从而提高浙江省森林生态系统的碳固定 能力。

\section{2 浙江省森林生态系统碳储量的分配特征}

森林土壤碳库作为森林生态系统最大的碳库, 在维持森林生态系统碳平衡和碳循环方面起着关键 
作用。周玉荣等(2000)针对全国森林生态系统碳储 量的研究表明, 土壤碳库约为植被碳库的3.39倍。李 克让等(2003)通过CEVSA模型估算, 我国森林生态 系统土壤碳库约为植被碳库的2.62倍。本研究结果 表明, 浙江省森林生态系统土壤碳库约为植被碳库 的3.23倍, 与周玉荣等(2000)的研究结果相近。

森林调落物是森林生态系统的重要组成部分之 一, 是森林土壤有机碳和养分的重要来源, 对于林 地土壤肥力的维护和森林生产力的提高具有重要作 用。据估计, 全球通过调落物分解归还到土壤的有 机碳约为 $50 \mathrm{Pg} \cdot \mathrm{a}^{-1}$ (彭少麟和刘强, 2002)。我国森林 生态系统调落物层平均碳密度为 $8.21 \mathrm{t} \cdot \mathrm{hm}^{-2}$ (周玉 荣等, 2000)。吉林省森林生态系统调落物层平均碳 密度为 $5.64 \mathrm{t} \cdot \mathrm{hm}^{-2}$ (王新问等, 2011)。本研究结果显 示: 浙江省森林生态系统调落物层平均碳密度低于 全国平均碳密度和吉林省调落物层碳密度, 这主要 因为调落物的现存量很大程度依赖于所处区域的水 热条件、地域特点，一般随水热因子的改善而减小 (周玉荣等, 2000)。

本研究表明, 浙江省林下灌草层的碳储量和碳 密度(表3)都高于吉林省灌草层碳储量(5.20 Tg)和碳 密度 $\left(0.64 \mathrm{t} \cdot \mathrm{hm}^{-2}\right.$ ) (王新闯等, 2011), 以及陕西省灌 草层碳储量 $(9.06 \mathrm{Tg})$ 和碳密度 $\left(1.42 \mathrm{t} \cdot \mathrm{hm}^{-2}\right.$ ) (崔高阳 等, 2015), 说明浙江省林下灌草具有较强的固碳能 力。以往众多基于森林资源清查资料在全国或区域 尺度上的森林生态系统碳储量的研究多针对乔木层 和土壤层, 而对林下植被和调落物的研究不多。实 际上, 当乔木层郁闭度较低时, 林下植被生长较好, 特别是在南方水热条件较好、林下植物丰富时, 忽 略其生物量, 将低估森林碳储量。

\section{3 估算方法对森林生态系统碳储量估算的影响}

目前国内已开展了大量区域或者全国尺度上森
林生态系统碳储量的研究，由于估算方法不同，森 林碳储量的估算还存在很大的不确定性(周玉荣等, 2000; Fang et al., 2001; 王效科等, 2001; 李克让等, 2003; Pan et al., 2004)。基于1989-1993年全国森林 资源清查资料，Pan等(2004)利用我国不同森林类型 分龄组的森林生物量估算模型估算的中国森林乔木 碳储量为 $4020.00 \mathrm{Tg}$, 而方精云等(2001)利用未考 虑林龄的蓄积量-生物量方程估算的结果为 4630.00 $\mathrm{Tg}$ ，后者比前者高估了 $610.00 \mathrm{Tg}$ 。基于全国第七次 资源清查资料，李海奎等(2011)利用不同树种的生 物量经验模型估算了中国森林植被碳储量, 其中吉 林省乔木碳储量为513.26 Tg, 而王新闯等(2011)利 用Pan等(2004)建立的模型估算的结果为 $439.15 \mathrm{Tg}$, 李海奎和雷渊才(2010)利用方精云等建立的模型估 计得到吉林省乔木碳储量为494.47 Tg (表7)。从以 上分析可以看出，不同的森林生物量估算方法给森 林植被碳储量的估算带来了很大的不确定性。未来 在进行国家及区域尺度碳循环研究时，应加强对各 种估算方法的评价篮选，采用统一合理的方法进行 碳储量的估算, 以减少估算方法带来的不确定性。

本研究利用2011-2012年野外标准地实测资料, 结合第八次全国森林资源清查资料, 研究了浙江省 森林生态系统碳储量、碳密度及其各组分的空间分 布特征，为评价浙江省森林的碳汇潜力提供了基础 数据, 但森林碳储量的估算精度仍有进一步提高的 可能性。蓄积量-生物量转换模型对森林碳储量估算 精度影响很大, 本研究采用的没有考虑林龄的蓄积 量-生物量模型可能会在一定程度上高估森林碳储 量, 因而在建立不同林分类型蓄积量-生物量模型 时，应尽可能考虑区域性和林龄。同时，某些森林类 型由于没有建立相应的蓄积量-生物量模型而采用 相似树种模型，降低了森林碳储量的估算精度。

表7 不同估算方法估算森林植被碳储量

Table 7 Estimation of forest carbon storage by using different biomass estimation models

\begin{tabular}{|c|c|c|c|}
\hline 研究区域 & 估算方法 & 植被碳储量 & 资料来源 \\
\hline Study area & Biomass estimation model & Forest carbon storage (Tg) & Reference \\
\hline 中国 China & $\begin{array}{l}\text { 分龄组森林蓄积量-生物量转换模型 } \\
\text { Age-based volume-to-biomass method }\end{array}$ & 4020.00 & Pan et al., 2004 \\
\hline 中国 China & $\begin{array}{l}\text { 不分龄组森林蓄积量-生物量转换模型 } \\
\text { Volume-to-biomass method }\end{array}$ & 4630.00 & Fang et al., 2001 \\
\hline 吉林省 Jilin Province, China & $\begin{array}{l}\text { 分龄组森林蓄积量-生物量转换模型 } \\
\text { Age-based volume-to-biomass method }\end{array}$ & 439.14 & Wang et al., 2011 \\
\hline 吉林省 Jilin Province, China & $\begin{array}{l}\text { 不分龄组森林蓄积量-生物量转换模型 } \\
\text { Volume-to-biomass method }\end{array}$ & 494.47 & Li \& Lei, 2010 \\
\hline 吉林省 Jilin Province, China & $\begin{array}{l}\text { 生物量经验模型 } \\
\text { Biomass regression model }\end{array}$ & 513.26 & Li et al., 2011 \\
\hline
\end{tabular}


基金项目 中国科学院战略性先导科技专项(XDA05050204)。

致谢 感谢中国科学院植物研究所邴艳红和刘晓娟 以及西南林业大学徐远杰等的帮助。

\section{参考文献}

Asner GP, Powell GVN, Mascaro J, Knapp DE, Clark JK, Jacobson J, Kennedy-Bowdoin T, Balaji A, Paez-Acosta G, Victoria E, Secada L, Valqui M, Hughes RF (2010). Highresolution forest carbon stocks and emissions in the Amazon. Proceedings of the National Academy of Sciences of the United States of America, 107, 16738-16742.

Cui GY, Chen YM, Cao Y, An CC (2015). Analysis on carbon stock distribution patterns of forest ecosystems in Shaanxi Province. Chinese Journal of Plant Ecology, 39, 333-342. (in Chinese with English abstract) [崔高阳, 陈云明, 曹 扬, 安淳淳 (2015). 陕西省森林生态系统碳储量分布格 局分析. 植物生态学报, 39, 333-342.]

Dixon RK, Solomon AM, Brown S, Houghton RA, Trexier MC, Wisniewski J (1994). Carbon pools and flux of global forest ecosystems. Science, 263, 185-190.

Fang JY, Chen AP, Peng CH, Zhao SQ, Ci LJ (2001). Changes in forest biomass carbon storage in China between 1949 and 1998. Science, 292, 2320-2322.

Fang JY, Guo ZD, Piao SL, Chen AP (2007). Terrestrial vegetation carbon sinks in China, 1981-2000. Science in China Series D: Earth Sciences, 50, 1341-1350.

Fang JY, Piao SL, Zhao SQ (2001). The carbon sink: The role of the middle and high latitudes terrestrial ecosystems in the northern hemisphere. Acta Phytoecologica Sinica, 25, 594-602. (in Chinese with English abstract) [方精云, 朴 世龙, 赵淑清 (2001). $\mathrm{CO}_{2}$ 失汇与北半球中高纬度陆地 生态系统的碳汇. 植物生态学报, 25, 594-602.]

Li HK, Lei YC (2010). Estimation and Evaluation of Forest Biomass Carbon Storage in China. China Forestry Publishing House, Beijing. (in Chinese) [李海奎, 雷渊才 (2010). 中国森林植被生物量和碳储量评估. 中国林业 出版社, 北京.]

Li HK, Lei YC, Zeng WS (2011). Forest carbon storage in China estimated using forestry inventory data. Scientia Silvae Sinicae, 47(7), 7-12. (in Chinese with English abstract) [李海奎, 雷渊才, 曾伟生 (2011). 基于森林清查 资料的中国森林植被碳储量. 林业科学, 47(7), 7-12.]

Li KR, Wang SQ, Cao MK (2003). Vegetation and soil carbon storage in China. Science in China Series D: Earth Sciences, 33, 72-80. (in Chinese) [李克让, 王绍强, 曹明奎 (2003). 中国植被和土壤的碳咜量. 中国科学(D 辑), 33, 72-80.]

Liu GH, Fu BJ, Fang JY (2000). Carbon dynamics of Chinese forests and its contribution to global carbon balance. Acta
Ecologica Sinica, 20, 733-740. (in Chinese with English abstract) [刘国华, 傅伯杰, 方精云 (2000). 中国森林碳 动态及其对全球碳平衡的贡献. 生态学报, 20, 733740.]

Liu GS, Jiang NH, Zhang LD, Liu ZL (1996). Soil Physical and Chemical Analysis Description of Soil Profiles. China Standard Press, Beijing. 24. (in Chinese) [刘光崧, 蒋能 慧, 张连第, 刘兆礼 (1996). 土壤理化分析与剖面描述. 中国标准出版社, 北京. 24.]

Liu QX, Chang J, Jiang B, Yuan WG, Qi LZ, Zhu JR, Ge Y, Shen Q (2005). The biomass of the evergreen broad-leaved ecological public-welfare forests in Zhejiang, East China. Acta Ecologica Sinica, 25, 2139-2144. (in Chinese with English abstract) [刘其霞, 常杰, 江波, 袁位高, 戚连忠, 朱F锦茹, 葛港, 沈其 (2005). 浙江省常绿阔叶生态公益 林生物量. 生态学报, 25, 2139-2144.]

Liu SN, Zhou T, Wei LY, Su Y (2012). The spatial distribution of forest carbon sinks and sources in China. China Science Bulletin, 57, 943-950. (in Chinese) [刘双娜, 周涛, 魏林 艳, 舒阳 (2012). 中国森林植被的碳汇/源空间分布格 局. 科学通报, 57, 943-950.]

Lü CQ, Sun SC (2004). A review on the distribution patterns of carbon density in terrestrial ecosystems. Acta Phytoecologica Sinica, 28, 692-703. (in Chinese with English abstract) [吕超群, 孙书存 (2004). 陆地生态系统碳密 度格局研究概述. 植物生态学报, 28, 692-703.]

Malhi Y, Baldocchi DD, Jarvis PG (1999). The carbon balance of tropical, temperate and boreal forests. Plant, Cell \& Environment, 22, 715-740.

Norby RJ, Luo YQ (2006). Evaluating ecosystem responses to rising atmospheric $\mathrm{CO}_{2}$ and global warming in a multiactor world. New Phytologist, 162, 281-293.

Pan YD, Birdsey RA, Fang JY, Houghton R, Kauppi PE, Kurz WA, Phillips OL, Shvidenko A, Lewis SL, Canadell JG, Ciais P, Jackson RB, Pacala SW, McGuire DA, Piao SL, Rqutiainen A, Sitch S, Hayes D (2011). A large and persistent carbon sink in the world's forests. Science, 333, 988-993.

Pan YD, Luo TX, Birdsey R, Hom J, Melillo J (2004). New estimates of carbon storage and sequestration in China's forests: Effects of age-class and method on inventorybased carbon estimation. Climate Change, 67, 211-236.

Peng SL, Liu Q (2002). The dynamics of forest litter and its responses to global warming. Acta Ecologica Sinica, 22, 1534-1544. (in Chinese with English abstract) [彭少麟, 刘强 (2002). 森林调落物动态及其对全球变暖的响应. 生态学报, 22, 1534-1544.]

Pope $\mathrm{J}$ (2006). How can global warming be traced to $\mathrm{CO}_{2}$ ? Scientific American, 195(6), 124.

Ren H, Li L, Liu Q, Wang X, Li YD, Hui DF, Jian SG, Wang J, Yang H, Lu HF, Zhou GY, Tang XL, Zhang QM, Wang

www.plant-ecology.com 
D, Yuan LL, Chen XB (2014). Spatial and temporal patterns of carbon storage in forest ecosystems on Hainan Island, southern China. PLoS ONE, 9(9), e108163.

Rind D (1999). Complexity and climate. Science, 284, 105-107.

Schimel DS (1995). Terrestrial ecosystems and the carbon cycle. Global Change Biology, 1, 77-91.

Simpson LG, Botkin DB, Nisbet RA (1993). The potential aboveground carbon storage of North American forests. In: Wisniewski J, Sampson RN eds. Terrestrial Biospheric Carbon Fluxes Quantification of Sinks and Sources of $\mathrm{CO}_{2}$. Springer, Netherlands. 197-205.

Vitousek PM (1994). Beyond global warming: Ecology and global change. Ecology, 75, 1861-1876.

Wang XC, Qi G, Yu DP, Zhou L, Dai LM (2011). Carbon storage, density, and distribution in forest ecosystems in Jilin Province of Northeast China. Chinese Journal of Applied Ecology, 22, 2013-2020. (in Chinese with English abstract) [王新闯, 齐光, 于大炮, 周莉, 代力民 (2011). 吉林省森林生态系统的碳储量、碳密度及其分布. 应用 生态学报, 22, 2013-2020.]

Wang XK, Feng ZW, Ouyang ZY (2001). Vegetation carbon storage and density of forest ecosystems in China. Chinese Journal of Applied Ecology, 12, 13-16. (in Chinese with English abstract) [王效科, 冯宗炜, 欧阳志云 (2001). 中国森林生态系统的植物碳储量和碳密度研究. 应用 生态学报, 12, 13-16.]

Watson RT, Noble IR, Bolin B, Ravindranath NH, Verardo DJ, Dokken DJ (2000). Land Use, Land-Use Change, and Forestry: A Special Report of the Intergovernmental Panel on Climate Change (IPCC). Cambridge University Press, Cambridge, UK.

Zeng WS (2005). Research on forest biomass and productivity in Yunnan. Central South Forest Inventory and Planning, 24(4), 1-3, 13. (in Chinese with English abstract) [曾伟生 (2005). 云南省森林生物量与生产力研究. 中南林业调 查规划, 24(4), 1-3, 13.]

Zhang F, Du Q, Ge HL, Liu AX, Fu WJ, Ji BY (2012). Spatial distribution of forest carbon in Zhejiang Province with geostatistics based on CFI sample plots. Acta Ecologica
Sinica, 32, 5275-5286. (in Chinese with English abstract) [张峰, 杜群, 葛宏立, 刘安兴, 傅伟军, 季碧勇 (2012). 基于地统计学和CFI样地的浙江省森林碳空间分布研 究. 生态学报, 32, 5275-5286.]

Zhang J, Ge Y, Chang J, Jiang B, Jiang H, Peng CH, Zhu JR, Yuan WG, Qi LZ, Yu SQ (2007). Carbon storage by ecological service forests in Zhejiang Province, subtropical China. Forest Ecology and Management, 245, 64-75.

Zhang J, Yuan WG, Ge Y, Jiang B, Zhu JR, Shen AH, Chang J (2010). Carbon storage and its sequestration potential by ecological service forest in Zhejiang. Acta Ecologica Sinica, 30, 3839-3848. (in Chinese with English abstract) [张骏, 袁位高, 葛港, 江波, 朱锦茹, 沈爱华, 常杰 (2010). 浙江省生态公益林碳储量和固碳现状及潜力. 生态学报, 30, 3839-3848.]

Zhang MZ, Wang GX (2008). The forest biomass dynamics of Zhejiang Province. Acta Ecologica Sinica, 28, 5665-5674. (in Chinese with English abstract) [张茂震, 王广兴 (2008). 浙江省森林生物量动态. 生态学报, 28, 56655674.]

Zhang MZ, Wang GX, Liu AX (2009). Estimation of forest biomass and net primary production for Zhejiang Province based on continuous forest resources inventory. Scientia Silvae Sinicae, 45(9), 13-17. (in Chinese with English abstract) [张茂震, 王广兴, 刘安兴 (2009). 基于森林资源 连续清查资料估算的浙江省森林生物量及生产力. 林 业科学, 45(9), 13-17.]

Zhao M, Zhou GS (2004). Carbon storage of forest vegetation and its relationship with climatic factors. Scientia Geographica Sinica, 24, 50-54. (in Chinese with English abstract) [赵敏, 周广胜 (2004). 中国森林生态系统的 植物碳咜量及其影响因子分析. 地理科学, 24, 50-54.]

Zhou YR, Yu ZL, Zhao SD (2000). Carbon storage and budget of major Chinese forest types. Acta Phytoecologica Sinica, 24, 518-522. (in Chinese with English abstract) [周玉荣, 于振良, 赵士洞 (2000). 我国主要森林生态系统碳咜量 和碳平衡. 植物生态学报, 24, 518-522.]

特邀编委: 韩士杰 责任编辑: 王 蒇

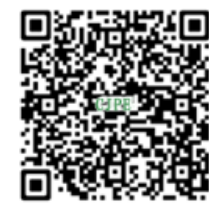

植物生态学报官网 唯一投稿网址

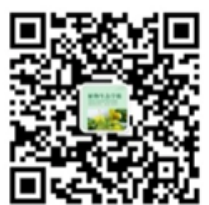

微信订阅号

期刊及学科 相关信息发布

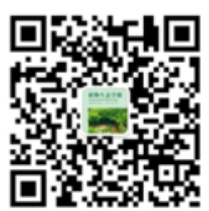

微信服务号

稿件状态查询

全文检索浏览 